\title{
Propuestas artísticas de las artes visuales del Ecuador desde la segunda mitad del siglo $\mathrm{XX}$ hasta la actualidad
}

\section{Artistic proposals of visual arts of Ecuador since the second half of the twentieth century to the present}

\author{
Christian PÉREZ-Avilés \\ Universidad de Especialidades Espíritu Santo- Guayaquil -Ecuador \\ capere@uees.edu.ec \\ Martha Rizzo-GonZÁLEZ \\ Universidad de Especialidades Espíritu Santo- Guayaquil -Ecuador \\ mfrizzo@uees.edu.ec
}

Recibido: 19 de enero de 2015

Aprobado: 18 de marzo de 2015

\begin{abstract}
Resumen
Este artículo es resultado de un trabajo de investigación que analiza las propuestas artísticas más importantes de las Artes Visuales en el Ecuador, desde la segunda mitad del siglo XX hasta la actualidad. Mediante revisión bibliográfica y recolección de datos que se realizó en la ciudad de Guayaquil, se pudo determinar su influencia e impacto en el circuito del arte actual. Los instrumentos que se utilizaron para la recolección de la información fueron entrevistas a profundidad que se ejecutaron a expertos en el tema. Al igual que las encuestas realizadas a los asistentes a diferentes eventos artísticos (exposiciones, muestras permanentes, seminarios), permitió establecer los intereses sociales de dichas propuestas. La metodología empleada tuvo un enfoque mixto, se utilizaron datos cuantitativos y cualitativos.

Palabras clave: intereses sociales, propuestas artísticas, evolución, artes visuales.
\end{abstract}

Pérez-Avilés, C., Rizzo-González, M. (2016): Propuestas artísticas de las artes visuales del Ecuador desde la segunda mitad del siglo XX hasta la actualidad. Arte, Individuo y Sociedad, 28(1) 139-154

\begin{abstract}
This article is the result of a research that analyzes the most important artistic proposals of Visual Arts in Ecuador, since the second half of the twentieth century to the present. Through literature review and data collection held in the city of Guayaquil, we could determine their influence and impact on the circuit of contemporary art. The instruments used for data collection were depth interviews that were done to experts in the field. Like surveys of attendees at different artistic events (exhibitions, permanent exhibitions, seminars), allowed to establish the social interests of those proposals. The methodology was mixed approach, quantitative and qualitative data were used. Keywords: realism, abstraction, Querelle des Anciens et des Modernes, pluralism, end of art.
\end{abstract}


Sumario: 1. Introduccion, 2. Antecedentes, 3. Artes visuales en el Ecuador desde los años 50 hasta la actualidad, 3.1. Realismo Social, 3.2. Naturalismo, 3.3. Expresionismo, 3.4. Informalismo, 3.5. Formalismo, 3.6. Feísmo, 3.7. Magicismo, 3.8. Conceptualismo, 3.9. Nuevo Expresionismo, 3.10. Constructivismo, 4. Autores Relevantes, 5. Arte Contemporáneo en Ecuador, 6. Tendencias artísticas preferentes de la población guayaquileña, 7. Temáticas preferentes de la población guayaquileña, 8. Obras relevantes según la población consultada, 9. Sondeo a expertos a través de entrevistas, 10. Intereses sociales, 10.1 Temáticas, 10.2. Búsquedas formales, 10.3. Propuestas conceptuales, 11. Conclusiones. Referencias.

\section{Introducción}

El arte es una manifestación poderosa de la humanidad, un lenguaje que, a lo largo de la historia, ha logrado plasmar la realidad y sus diferentes aspectos de maneras revolucionarias; muchas veces proponiendo soluciones a diferentes necesidades, convirtiéndose en una alternativa válida para el desarrollo del pensamiento humano, la creatividad y la innovación.

Los artistas siempre han mostrado un modo vanguardista de entender el mundo, abriendo las puertas a visiones humanistas, filosóficas, sociales y a la valoración del trabajo que se hace con las manos y la habilidad para plasmar con delicadeza artística la visión subjetiva del mundo y lo que contiene. Desde los ojos de los artistas de la historia, somos capaces de observar la evolución del pensamiento con mucha facilidad

En Latinoamérica, el arte originario de nuestros pueblos se fusiona con las manifestaciones traídas por los conquistadores, generando un híbrido bastante rico entre la cosmovisión indígena y la cultura europea; tendencia que prevalecerá en la producción artística de nuestro continente durante siglos, hasta que, durante el Siglo $\mathrm{XX}$, con el nacimiento de las vanguardias locales, se inicie la exploración de un arte más propio.

En el Ecuador, este proceso de cambio se produce durante la segunda mitad del Siglo XX, cuando la mentalidad innovadora de artistas como Eduardo Kingman, Oswaldo Guayasamín y otros, logran crear estilos que, aunque al principio no fueran aceptados, llevarían el nombre del Ecuador a esferas artísticas de gran envergadura e importancia.

Sin embargo, este auge del arte ecuatoriano no se vuelve a repetir en la historia con la misma intensidad, relegando las tendencias posteriores a un segundo plano, y llevando a la población consumidora de arte, especialmente a las personas desligadas de los círculos intelectuales, a la repetición de los éxitos artísticos de aquella época doradas, privándose de la novedad y riqueza conceptual de las propuestas contemporáneas.

En el presente estudio se abordó este fenómeno desde la perspectiva de las preferencias sociales, con la finalidad de desentrañar los ejes temáticos que, tanto de la época antigua como de las manifestaciones contemporáneas, han llegado a ocupar un espacio en la memoria visual ecuatoriana, para determinar su importancia y poder entender cómo y cuándo se produce esta ruptura de criterios. 


\section{Antecedentes}

El medio cultural ecuatoriano en la actualidad, se encuentra permeado por las propuestas desarrolladas en el siglo XX, especialmente entre los años 50, 60 y 70 . Estas propuestas marcaron de tal forma el arte local, que su influencia resulta casi indeleble en la mentalidad de los espectadores, volviéndose difícil para el arte actual establecer influencias nuevas o dialogar con las propuestas anteriores.

La memoria de los consumidores de arte, en cuanto a artistas y propuestas, se termina en el Indigenismo de Guayasamín y otros creadores, que adorna las casas a través de reproducciones y plagios que se venden en mercados y calles, desprestigiando y desluciendo la obra de artistas importantes de la historia del arte ecuatoriano, que se han convertido en simples lugares comunes.

Las tendencias, corrientes y las propuestas artísticas siempre se han desarrollado sin estudiar su origen, abordando temáticas extranjeras y, al mismo tiempo, recuperando de alguna forma el fondo tradicional y ancestral de la producción precolombina en nuestro territorio.

Ecuador posee varias tendencias que han marcado su historia artística, especialmente si consideramos el punto coyuntural, en los años 50 del Siglo XX, cuando los artistas vuelcan sus intereses hacia la realidad social y lo autóctono.

Es en ese momento cuando nacen las propuestas ecuatorianas como tales, alejadas de los presupuestos coloniales o republicanos, y se inicia la exploración de una iconografía propia.

Sin embargo, ya por la importancia de esas corrientes o su novedad en el tiempo, resulta interesante cómo, con el pasar de las décadas, las propuestas siguientes no logran tener el impacto suficiente en la memoria de los observadores y, por qué no decirlo, en la memoria de los mismos productores; empezando a producirse una especie de letargo visual o estancamiento, que provoca una repetición constante de símbolos y tendencias, frenando el desarrollo de la memoria visual del Ecuador.

Poco o nada se ha estudiado sobre estos fenómenos. Los historiadores del arte ecuatoriano se han limitado a reseñar las propuestas de tales o cuales artistas, sin ahondar en las búsquedas intrínsecas que componen los intereses de cada época.

Si bien es cierto se han desarrollado estudios iconográficos, entre los que se destaca la exposición "Umbrales del Arte en el Ecuador" (MAAC, 2005), desarrollada en la primera década del presente siglo por el conjunto de investigadores del Museo Antropológico y de Arte Contemporáneo, pero sin llegar a indagar la naturaleza de las propuestas artísticas visuales.

Este estudio pretende abrir un nuevo campo investigativo, mucho más profundo y objetivo frente a un tema que se encuentra poco explorado y evaluado.

Revalorizar las tendencias antiguas, estudiar el estado de la memoria visual y evaluar el impacto de las propuestas actuales resulta imperativo, necesario y urgente en el momento actual de nuestra cultura.

Cuando hablamos de la naturaleza de las propuestas artísticas visuales, nos referimos al estudio del sentido. Es decir, el análisis profundo de la producción humana, con la finalidad de identificar los signos presentes en los sistemas de comunicación, teniendo en cuenta que toda producción manifiesta la intención de su autor y las diferentes dimensiones de su subjetividad. 
Para desentrañar estas simbologías, podemos acudir a la semiótica que asiste al fondo de los diferentes lenguajes que se utilizan para construir los significados, interpretando de los siguientes componentes: significante, significado y referente; siguiendo las teorías planteadas por Charles S. Peirce, quien afirma que el signo se compone de un soporte material (significante), una imagen mental o idea (significado) y el objeto que recibe el sentido (referente) (Von der Walde Moheno, 1990).

Ya que las artes visuales poseen una finalidad comunicativa, pueden ser entendidas en términos de lenguaje y convertirse en sujeto de análisis semiótico. Sin embargo, dada la movilidad de los símbolos, mirar las artes visuales desde una perspectiva semiótica resulta bastante complejo.

En primer lugar, no se trata de revisar las imágenes que aparecen en las diferentes obras pictóricas de tal o cual período, porque se caería en terrenos ya explorados por otras disciplinas, como la iconología o la iconografía; se trata de analizar los mecanismos que construyen la percepción visual.

En esta tarea, la brecha existente entre las artes tradicionales y las contemporáneas se vuelve bastante evidente: las primeras poseen símbolos explícitos, colocados deliberadamente por los autores para dar a entender cosas o transmitir lenguajes. Un claro ejemplo de esto lo podemos observar en el arte de la Escuela Quiteña, cuya finalidad simbólica es la evangelización.

En cuanto al arte contemporáneo, la tarea es mucho más fácil, porque las obras son, en sí mismas, estudios semióticos que se arraigan en otros campos (filosóficos, sociológicos, psicológicos, etc.). Por ejemplo, la obra de René Magritte resulta en sí misma un análisis del vínculo entre el lenguaje visual y el lenguaje escrito al plantear en su obra que los objetos que se observan en una obra de arte no son reales, sino en la mente de quien los observa (Magritte, 1929).

Ya lo advertía Umberto Eco en su ensayo Perspectivas de una semiótica de las artes visuales:

El arte contemporáneo no es más complejo, sino más simple que el arte tradicional, y si parece de difícil comprensión es precisamente porque se concentra de manera ascética en modalidades productivas aisladas, llevando cada una de ellas al máximo de sus posibilidades. El arte contemporáneo se manifiesta así, y sobre todo, como laboratorio semiótico, o ejercicio metalingüistico, mientras que el arte tradicional hablaba o fingía hablar lenguajes ya constituidos — también cuando los estaba innovando (Eco, 2007:64).

\section{Artes visuales en el Ecuador desde los años 50 hasta la actualidad}

El siglo XX de las artes en el Ecuador inicia con un retraso considerable, en la década del 30, cuando tres artistas (Pedro León, Camilo Egas y José Moscoso) introducen en el medio local las corrientes de las primeras vanguardias: cubismo, expresionismo y realismo. Las tendencias artísticas que aparecen en el Ecuador a partir de la década del 50 en el siglo XX son las siguientes: 


\subsection{Realismo Social}

Esta tendencia toma las características del Muralismo Mexicano de la década del 30 y 40. Su origen tiene que ver con la obra de Eduardo Kingman, titulada "El Carbonero", en la que el autor presenta un retrato de la clase obrera explotada, denunciando la injusticia social y el estado de abandono de las clases sociales más pobres del país.

\subsection{Naturalismo}

Partiendo del Realismo Social, los autores profundizan mucho más en su búsqueda de retratar las situaciones sociales, llegando a poner sus ojos en el naturalismo, que se desarrollaba en Francia. Con esta base ideológica, se inicia la exploración de problemas como el alcoholismo, la prostitución, la violencia y la pobreza. Esta tendencia naturalista será conocida como "Indigenismo".

\subsection{Expresionismo}

El Indigenismo se transforma en dinámica común y en hilo conductor del arte ecuatoriano, y busca nuevas formas de manifestarse. Los artistas posan su mirada en el Expresionismo Alemán, dándole a sus obras mayor carga emocional. No se trata solamente de representar o retratar la realidad, sino de narrarla desde las profundidades del ser. Así, las obras empiezan a mostrar no solo las características externas de los personajes, sino que buscan representar sus realidades internas, valiéndose de nuevas formas, colores más puros, líneas más crudas y una pincelada más gestual. Se trata de una pintura que siente, que desnuda la realidad sin temor, que irrumpe en los salones con vehemencia, en un momento en que las artes solo pertenecían a las clases sociales altas.

\subsection{Informalismo}

A partir de la década del 60 se desarrolla una corriente abstracta, basada en el Informalismo Europeo. Esta corriente toma en Latinoamérica el nombre de "Ancestralismo". Si bien es cierto que la inspiración ideológica proviene del exterior, los artistas logran aterrizarla con éxito en la realidad ecuatoriana al desarrollarla a partir de estudios de las artes ancestrales de las culturas precolombinas.

Una característica importante de esta tendencia es la ausencia de significados evidentes. Los artistas recurren a la abstracción lírica, dejando que los espectadores completen sus obras desde su propia visión. No se trata más de mostrar realidades concretas.

\subsection{Formalismo}

Luego de décadas de buscar significados a partir de las obras de arte, los artistas ecuatorianos se lanzan a la búsqueda de estudios formales, dejando de lado la crítica social y los asuntos éticos para embarcarse en exploraciones en cuanto a la composición, forma, color y estructura de sus obras. 
Se abordan cuestiones geométricas, constructivistas y se emplean recursos como el collage y el ensamblaje.

\subsection{Feísmo}

Ante la debacle económica del Ecuador en los años 80, los artistas inauguran un tipo diferente de figuración, esta vez con total intransigencia y descaro. El feísmo en el Ecuador hace eco a otras tendencias latinoamericanas que acuden al dibujo descarnado y la pintura oscura de la Serie Negra de Goya.

Con esta tendencia florece el grabado ecuatoriano, por su capacidad representativa dramática y los bajos costos de producción y reproducción. Es la época en que los medios de comunicación y la publicidad inician la explotación de la imagen por la imagen.

\subsection{Magicismo}

Ante la crudeza y la fealdad de las obras de arte de finales de los 70 e inicio de los 80 , surge un grupo reaccionario que se interna en los territorios de lo mágico y sublime. El Magicismo es una suerte de Surrealismo que no está controlado por los sueños, sino por la búsqueda de una perfección estética en cuanto al ritmo, el color y la composición. El objetivo es claro: dejar de lado la tendencia al horror y devolver al arte su característica estética.

\subsection{Conceptualismo}

El arte conceptual coloca mayor importancia a las ideas que constituyen los sentidos dentro de la obra de arte que a la obra en sí misma. En algunos casos, incluso sucede que la obra es la idea, y no posee un soporte definido. Este movimiento ingresa al país en la década de los 80 y rápidamente toma fuerza entre los jóvenes artistas, que consideraban que la corriente feísta carecía de relevancia y la magicista pecaba de soñadora.

Inspirados por los artistas conceptuales de los 70 en los Estados Unidos, estos artistas apuestan por imponer un nuevo lenguaje visual, mucho más irónico, con la finalidad de desnudar los procesos artísticos, devolviéndoles su importancia.

\subsection{Nuevo Expresionismo}

Se trata de una revisión de dos tendencias importantes: el naturalismo y el expresionismo, dando como lugar obras de fuerte carácter caricaturesco y, a, mismo tiempo de carga expresionista por los brochazos fuertes, el dripping y la crítica social. Aparece un erotismo abordado de manera cruda y directa, sin tapujos, sin miedo de caer en el grotesco.

\subsection{Constructivismo}

Tomando las características de la abstracción geométrica, ciertos artistas se preocupan por las formas arquitectónicas y superficies modeladas. Además, utilizan recursos matemáticos, planos vectoriales, composiciones cambiantes y trampantojos. 


\section{Autores Relevantes}

Luego de haber distinguido las diez tendencias más significativas de la segunda mitad del Siglo XX, es necesario identificar los autores más relevantes de esa época, teniendo en cuenta que las tendencias artísticas se encuentran marcadas de acuerdo a la década a la que corresponden y pueden ser agrupadas en cuatro bloques claros, como se muestra en la Tabla 1.

Tabla 1.

Autores relevantes de cada período artístico desde la década del 50 hasta la década del 90 del Siglo XX

\begin{tabular}{cccc}
\hline $\begin{array}{c}\text { Realismo Social } \\
\text { Naturalismo } \\
\text { Expresionismo }\end{array}$ & $\begin{array}{c}\text { Informalismo } \\
\text { Formalismo }\end{array}$ & $\begin{array}{c}\text { Feísmo } \\
\text { Magicismo }\end{array}$ & $\begin{array}{c}\text { Conceptualismo } \\
\text { Nuevo Expresionismo } \\
\text { Constructivismo }\end{array}$ \\
(década del 50) & (década del 60) & (década del 70) & (décadas del 80 y 90) \\
\hline Eduardo Kingman & Enrique Tábara & Ramiro Jácome & Perugachi \\
Oswaldo Guayasamín & Osvaldo Viteri & Nelson Román & José Cela \\
Jaime Andrade Moscoso & Aníbal Villacís & Hernán Zúñiga & Marcelo Tejada \\
Galo Galecio & Guillermo Muriel & Miguel Yaulema & Eloy Cumbe \\
Diógenes Paredes & Gilberto Almeida & Juan Villafuerte & Antonio Paredes \\
César Andrade Faini & Estuardo Maldonado & Mario Solís & Luigi Stornaiolo \\
Luis Moscoso & Theo Constante & Xonzalo Blum \\
José Enrique Guerrero & Humberto Moré & Robin Echanique & Jorge Velarde \\
Leonardo Tejada & Bolívar Peñafiel & Osvaldo Mora & Marcos Restrepo \\
Segundo Espinel & Luis Lara & Xavier Patiño \\
Bolívar Mena Franco & Judith Gutiérrez & Mariela García & José Cauja \\
Alba Calderón de Gil & Luis Miranda & Edgar Carrasco & Rodrigo Cuvi \\
Aracely Gilbert & Félix Aráuz & Roosevelt Cruz & Marco Alvarado \\
Eduardo Solá Franco & & & Francisco Valverde \\
& & & Manuel Cholango \\
& & & Larissa Marangoni \\
& & & Jenny Jaramillo \\
& & & Patricio Ponce \\
\hline & & &
\end{tabular}

Tabla 1. Elaborado por: Pérez,C \& Rizzo, M.

Fuente: Rodríguez Castello, H. (1988). El siglo XX de las artes visuales en el Ecuador.

\section{Arte Contemporáneo en Ecuador}

La última década del Siglo XX es el marco en el que surge el Arte Contemporáneo en Ecuador, dando lugar a una gran diversidad en la producción artística de los jóvenes creadores y también de los artistas de trayectoria que deciden inscribirse en las nuevas tendencias.

Manifestaciones como la instalación, el vídeo arte, la performance, el arte tierra y el arte social urbano se unen a las tendencias tradicionales que empiezan a ser releídas y reestructuradas. Todo el arte relevante del nuevo siglo tendrá una marcada tendencia reflexiva, una carga social (intrínseca o extrínseca) y la calidad de las obras 
irá creciendo con el paso del tiempo.

Una de las más grandes novedades de esta época será el cambio del modelo de trabajo artístico, ahora entendido desde el sistema de proyectos y desarrollado muchas veces por colectivos artísticos.

En esta época han surgido importantes artistas que se han encargado de escindir los discursos oficiales, e incluso alejarse de las instituciones tradicionales para desarrollar un arte más cercano a la sociedad e, irónicamente, más interesante para los estudiosos.

La recolección de datos se realizó en la ciudad de Guayaquil, entre los asistentes a diferentes eventos artísticos (exposiciones, muestras permanentes, seminarios), y se obtuvieron los siguientes resultados:

De las 203 personas encuestadas, el 33,33\% de los votos posibles señaló a Oswaldo Guayasamín como el artista más importante de la lista presentada. El segundo lugar le correspondió a Eduardo Kingman, con un total del 26,60\% y el tercer lugar a Gonzalo Endara Crow, con un 23,80\%.

Esto demuestra que la población reconoce con mucha relevancia los artistas de la década del 50 del Siglo XX (Guayasamín, Kingman) y desconoce las figuras artísticas actuales (Santillán, Córdova). En cuanto a otras personalidades, se destaca la figura de Gonzalo Endara Crow, cuya obra es de las más copiadas y plagiadas artesanalmente.

Los artistas de las década del 80 y 90 del Siglo XX poseen porcentajes muy bajos (Constante, Stornaiolo), a pesar de que sus propuestas son impactantes, novedosas y vanguardistas.

\section{Tendencias artísticas preferentes de la población guayaquileña}

Entre las tendencias destacadas como las más relevantes por la población encuestada, se establece en primer lugar el paisaje con un 31,03\%, mientras que el segundo y el tercer lugar lo ocupan el Realismo Social con un 27,09\% y el Arte Contemporáneo con un $14,12 \%$, como se refleja en la Tabla 2 :

Tabla 2.

Tendencias artísticas preferentes de la población consultada

\begin{tabular}{lrr}
\hline Tendencia Artística & Cantidad de votos & Porcentaje \\
\hline Paisaje & 189 & $31,03 \%$ \\
Realismo Social (Indigenismo) & 165 & $27,09 \%$ \\
Arte Contemporáneo & 86 & $14,12 \%$ \\
Arte Abstracto & 80 & $13,14 \%$ \\
Surrealismo & 44 & $7,23 \%$ \\
Expresionismo & 38 & $6,24 \%$ \\
Bodegón y Naturaleza Muerta & 7 & $1,15 \%$ \\
\hline TOTAL & 609 & $100 \%$ \\
\hline
\end{tabular}

Tabla 2. Elaborado por: Pérez,C \& Rizzo, M. Fuente: Encuestas realizadas a población asistente a exposiciones, muestras permanentes, seminarios en la ciudad de Guayaquil- Ecuador. 
Resultó interesante que la población escogiera como primera opción una tendencia que en el Ecuador sólo ha tenido finalidades ornamentales, como es el Paisaje. En realidad son pocos los autores que han aportado novedad a esta temática. Por ejemplo, Gonzalo Endara Crow es un gran innovador de la pintura paisajística latinoamericana al incorporar elementos novedosos y surrealistas en el mismo. Sin embargo, su obra no puede ser enmarcada solamente como Paisaje, ya que su búsqueda se encuentra enmarcada en lo que se denomina "Realismo Mágico Latinoamericano" o "Magicismo".

El Realismo Social aparece en segundo lugar, como era de esperarse luego de observar los resultados de la primera pregunta, en los que encontramos que sus dos mayores representantes (Guayasamín, Kingman) obtuvieron las puntuaciones más altas de la población consultada.

Lo más sorprendente, sin duda, es la aparición del Arte Contemporáneo en el tercer lugar, ya que los autores contemporáneos obtuvieron bajísimos porcentajes en cuanto a la valoración de criterios de la población al escoger los artistas plásticos más representativos Se podría decir que la población reconoce la importancia del Arte Contemporáneo y su relevancia en la escena artística, pero desconoce los nombres o las propuestas de los autores actuales.

De igual manera, la aparición en cuarto lugar del abstraccionismo es bastante interesante. Esto muestra que la población no rechaza tendencias alejadas de la figuración clásica, y gusta de manifestaciones del arte moderno.

El Surrealismo y el Expresionismo aparecen en la lista con porcentajes menores, lo cual no es ninguna sorpresa, ya que ambas expresiones se encuentran permeadas en otro tipo de propuestas de los artistas ecuatorianos (como el Magicismo de Endara, que incorpora elementos surreales).

\section{Temáticas preferentes de la población guayaquileña}

Al observar los resultados de la tercera pregunta, referida a las temáticas preferentes de la población consultada, se constata que el Paisaje obtiene el primer lugar con el $32,32 \%$. El segundo lugar lo ocupan los bodegones, con un $21,51 \%$ y el tercero es ocupado por los motivos florales, con un $20,20 \%$, como se puede ver en la tabla 3 .

Tabla 3.

Temáticas preferentes de la población consultada

\begin{tabular}{lrr}
\hline Temáticas & Cantidad de votos & Porcentaje \\
\hline Paisajes & 142 & $23,32 \%$ \\
Bodegones & 131 & $21,51 \%$ \\
Flores & 123 & $20,20 \%$ \\
Retratos Expresionistas & 91 & $14,94 \%$ \\
Caballos & 82 & $13,47 \%$ \\
Abstracción & 26 & $4,27 \%$ \\
Retratos Realistas & 12 & $1,97 \%$ \\
Arte precolombino & 2 & $0,33 \%$ \\
\hline TOTAL & 609 & $100 \%$ \\
\hline
\end{tabular}

Tabla 3. Elaborado por: Pérez,C \& Rizzo, M. Fuente: Encuestas realizadas a población asistente a exposiciones, muestras permanentes, seminarios. 
Sin duda, los resultados más interesantes se obtuvieron con esta pregunta, ya que las tres temáticas preferentes de la población consultada corresponden a cuestiones mayoritariamente ornamentales, lo que puede darnos una idea sobre el lugar que ocupa el arte en la mentalidad ecuatoriana.

El cuarto lugar lo ocupa el retratismo expresionista, cuyos representantes mayores (Guayasamín y Kingman) obtuvieron las puntuaciones más altas en la primera pregunta.

En esta pregunta no aparecen en absoluto tendencias contemporáneas, aunque sí aparecen otras cuestiones ornamentales típicas de nuestro medio artesanal (caballos, abstracción).

\section{Obras relevantes según la población consultada}

La última pregunta del cuestionario estaba basada en el reconocimiento de algunas obras relevantes para cada una de las etapas estudiadas en este trabajo de investigación. Las obras fueron seleccionadas por la representatividad dentro de las propuestas de un artista importante de cada época.

Este ejercicio arrojó resultados que, habiendo visto los correspondientes a preguntas anteriores, no resultan sorprendentes, como podemos constatar en la tabla.

Tabla 4.

Obras relevantes según la población consultada

\begin{tabular}{lrr}
\hline Obra & Cantidad de votos & Porcentaje \\
\hline "La Ternura" - Oswaldo Guayasamín & 102 & $50,25 \%$ \\
"Sin título" - Estuardo Maldonado & 7 & $3,45 \%$ \\
"Botica" - Juana Córdova & 11 & $5,42 \%$ \\
"Baile de amplio como de reconocido prestigio en el & 5 & $2,46 \%$ \\
medio" - Luiggi Stornaiolo & 78 & $38,42 \%$ \\
\hline "Sin título" - Gonzalo Endara Crow & 203 & $100 \%$ \\
\hline TOTAL & & \\
\hline
\end{tabular}

Tabla 4. Elaborado por: Pérez,C \& Rizzo, M. Fuente: Encuestas realizadas a población asistente a exposiciones, muestras permanentes, seminarios en la ciudad de Guayaquil- Ecuador.

Una vez más, los resultados evidencian la relevancia que tiene para la población la obra de Oswaldo Guayasamín, que ocupa el primer lugar con el 50,25\%. Gonzalo Endara Crow también vuelve a aparecer con fuerza, en el segundo lugar con $38,42 \%$, mientras los lugares siguientes poseen porcentajes menores.

\section{Sondeo a expertos a través de entrevistas}

Lo anteriormente expuesto podría desalentar a cualquier artista en formación, especialmente si consideramos que el incipiente mercado artístico ecuatoriano resulta limitado para desarrollar una obra que pueda venderse con facilidad y amplitud; mucho más si consideramos que las propuestas actuales no calan del todo en la mentalidad de la población mayoritaria que consume arte, quedando relegadas a un 
grupo de personas que, por su cercanía a los circuitos artísticos locales, conocen y entienden dichas propuestas.

Sin embargo algunos curadores y críticos de Arte en entrevistas concedidas durante el estudio expresaron que no están de acuerdo con la idea de que exista como tal un estancamiento en la memoria visual, por lo menos no de manera general. En sus apreciaciones coincidieron que el coleccionismo local ha evolucionado y las propuestas artísticas expresan discursos diferentes.

Esto tiene mucho sentido si miramos la naturaleza de las propuestas actuales y su novedad, muchas veces transgresora, muy lejana de los discursos oficiales y, sobre todo, grandilocuente y liberal.

En su libro "1998 - 2009 - HISTORIA(S) en el arte contemporáneo del Ecuador", el crítico de arte local Rodolfo Kronfle Chambers reseña una larga y productiva trama de sucesos, obras y tendencias que, durante la transición del siglo XX al XXI, marcaron los vaivenes del arte local. Según Kronfle (2009), la historia es un recurso valioso en la producción artística contemporánea, convirtiéndose en "plataforma reflexiva, herramienta discursiva, poética, crítica o referencial al interior de sus prácticas (de los artistas), imbuidos de un impulso revisionista y creador de disensos que se manifiesta por la necesidad de dar respuesta a problemas políticos, sociales y culturales que los rodean".

Y efectivamente, si miramos el panorama general de las artes en nuestro país, encontraremos una división clara entre lo que se hace con fines comerciales inmediatos y de manera artesanal, y lo que se produce como obra artística, se presenta en galerías, museos, certámenes y demás. En esos escenarios nunca encontraremos propuestas trasnochadas que plagien, reproduzcan o copien el estilo o los intereses de los maestros de antaño.

El llamado "Efecto Guayasamín" existe sin duda y se resucita a conveniencia de los promotores culturales, como denuncia X. Andrade (2011): "Es revelador que esta noción haya sido propuesta desde el diseño gráfico, para describir la proliferación de retratos de la miseria india patente en la decoración interior de las oficinas burocráticas, murales sindicalistas y mercados artesanales para turistas".

La obra de los maestros se esgrime con finalidades sociales, económicas, culturales o políticas para legitimar otros procesos o simplemente para vender. El estancamiento de la memoria visual no lo han producido los artistas, porque la producción se renueva siempre y explora imaginarios nuevos, realiza relecturas de la historia o genera puntos de debate, como característica lógica y típica del arte contemporáneo. Tampoco la ha producido la necesidad nostálgica de la población consumidora de arte que no quiere olvidar los grandes éxitos de su cultura, porque a pesar del desconocimiento las personas sí valoran lo nuevo y acuden con curiosidad a apreciarlo.

\section{Intereses sociales}

Una vez revisado el criterio de la población y los comentarios de algunos expertos, podemos realizar la última parte del estudio. Para elaborar una línea de tiempo que determine los intereses sociales. Se tomaron en cuenta tres elementos fundamentales: el objeto, su significado y el signo que crea en la mentalidad del receptor.

En primer lugar, se dividió las diez tendencias artísticas en grupos temáticos de 
acuerdo a su contenido, teniendo en cuenta que cada grupo temático corresponde a un objeto de estudio semiótico y, por ende, posee determinados significados que son comunes, sin importar la época, autores o características formales.

\subsection{Temáticas}

Un primer grupo temático se constituye con las propuestas que abordan estudios sociales y políticos, entre los que se pueden contar las siguientes: Realismo Social, Naturalismo (Indigenismo), Expresionismo y Nuevo Expresionismo.

Resulta curioso la brecha generacional que separa las tendencias mencionadas: el Realismo Social y el Naturalismo corresponden a la década del 50, mientras que el Expresionismo y el Nuevo Expresionismo se ubican entre los años 80 y 90 del siglo $\mathrm{XX}$. Esto es entendible, especialmente si tenemos en cuenta que las corrientes que se encuentran entre uno y otro grupo, corresponden a búsquedas e intereses bastante diferentes y, por lo tanto, podemos entender que, tanto el Expresionismo como el Nuevo Expresionismo cumplen una función de relectura y reposicionamiento, fenómeno normal en las artes contemporáneas que, en este caso, se adelanta un poco al aparecer en una época modernista para el arte ecuatoriano.

En cuanto a los tres elementos semióticos que constituyen el fondo de estas tendencias, podemos encontrarlos en la tabla 5.

Tabla 5.

Elementos semióticos de las propuestas sociales

\begin{tabular}{|c|c|c|}
\hline Objeto & Significado & Símbolo \\
\hline Indígena & $\begin{array}{ll}\text { - } & \text { Situación de pobreza } \\
\text { - } & \text { Ecuatorianidad } \\
\text { - } & \text { Identidad originaria } \\
& \text { Reivindicación de Latinoamérica }\end{array}$ & $\begin{array}{ll}\text { - } & \text { Lucha social } \\
\text { - } & \text { Patriotismo } \\
\text { - } & \text { Revolución }\end{array}$ \\
\hline Sufrimiento & $\begin{array}{ll}\text { - } & \text { Explotación } \\
\text { - } & \text { Ruptura con los ideales de belleza }\end{array}$ & $\begin{array}{ll}\text { - } & \text { Anti-capitalismo } \\
\text { - } & \text { Anti-imperialismo } \\
\text { - } & \text { Reivindicación histórica }\end{array}$ \\
\hline
\end{tabular}

Tabla 5. Elaborado por: Pérez,C \& Rizzo, M. Fuente: Encuestas realizadas a población asistente a exposiciones, muestras permanentes, seminarios en la ciudad de Guayaquil- Ecuador.

Las propuestas sociales, entonces, tienen un claro sentido político y fueron elaboradas en momentos coyunturales, contribuyendo a ideales cívicos, como la creación de una identidad nacional más sólida y una idea más incluyente de la ecuatorianidad.

Esto explica por qué las obras de estas características tienen tanta acogida entre los círculos de poder, llegando a convertirse en eje de la cultura hasta el día de hoy. Los murales de Guayasamín adornan el Pleno de la Asamblea Nacional y son motivo de orgullo de todos los ecuatorianos, por ejemplo.

Las obras de carácter social, además, generan una identificación muy grande con los espectadores. Basta observar, como cuestión curiosa, que la Capilla del Hombre, 
que acoge especialmente las pinturas correspondientes al Huacay Nan (Camino del llanto) y a la Edad de la Ira, las pinturas más descarnadas de Guayasamín, es uno de los puntos museográficos más visitados del Ecuador, superando incluso a grandes museos de la capital, como el Museo de la Ciudad o el Centro Cultural Metropolitano.

\subsection{Búsquedas formales}

Un segundo grupo temático se constituye con las propuestas que abordan búsquedas en el plano formal, enfocando su estudio en cuestiones como la composición, el color, el movimiento, etc. Las propuestas que forman parte de este grupo son las siguientes: Informalismo, Formalismo, Constructivismo.

Las dos primeras, corresponden a la década del 60 y la tercera a la década del 90 del siglo XX y, en ambos casos, son respuestas a las tendencias que reivindicaban los aspectos sociales. Se podría decir que constituyen un descanso o punto de quiebre frente a la figuración, explorando campos abstractos para tocar otro tipo de lenguajes, como se observa en la Tabla 6.

Tabla 6

Elementos semióticos de las búsquedas formales

\begin{tabular}{|c|c|c|}
\hline Objeto & Significado & Símbolo \\
\hline Color & $\begin{array}{ll}\text { - } & \text { Alegría } \\
\text { - } & \text { Armonía }\end{array}$ & $\begin{array}{ll}\text { - } & \text { Superación } \\
\text { - } & \text { Luminosidad } \\
\text { - } & \text { Vida }\end{array}$ \\
\hline Forma & $\begin{array}{ll}\text { - } & \text { Equilibrio } \\
\text { - } & \text { Diversidad }\end{array}$ & - $\quad$ Novedad \\
\hline
\end{tabular}

Tabla 6. Elaborado por: Pérez,C \& Rizzo, M. Fuente: Encuestas realizadas a población asistente a exposiciones, muestras permanentes, seminarios en la ciudad de Guayaquil Ecuador.

El cambio de lenguaje es evidente: no se trata de ideales políticos o sociales; se trata de búsquedas que pretenden convertirse en un descanso frente a la crudeza de las propuestas sociales, y lo logran apelando a cuestiones opuestas totalmente.

Sin embargo, ya que el recurso primordial es la abstracción, estos lenguajes quedan relegados a un segundo plano, como pudimos observar en los resultados de las encuestas.

\subsection{Propuestas conceptuales}

Este tercer grupo está constituido por búsquedas bastante diferentes en cuanto a las formas de expresión, pero resultan afines por el fondo desde el que se construyen.

Tanto el Magicismo y el Feísmo (Década del 70), como el Conceptualismo (Década del 90) y las Artes Contemporáneas, poseen fondos investigativos muy profundos y, se podría decir que cada obra se ejecuta en base a marcos teóricos elaborados, aunque varíen las temáticas, la ejecución y los lenguajes visuales, como se observa en la Tabla 7. 
Tabla 7.

Elementos semióticos de las propuestas conceptuales

\begin{tabular}{|c|c|c|}
\hline Objeto & Significado & Símbolo \\
\hline $\begin{array}{l}\text { Paisaje } \\
\text { (Magicismo) }\end{array}$ & $\begin{array}{ll}\text { - } & \text { Equilibrio } \\
\text { - } & \text { Belleza }\end{array}$ & - Valoración de la naturaleza \\
\hline $\begin{array}{l}\text { Surrealismo } \\
\text { (Magicismo, Feísmo) }\end{array}$ & $\begin{array}{ll}\text { - } & \text { Sensación de escape } \\
\text { - } & \text { Realidad alterada } \\
\text { - } & \text { Fantasía } \\
\text { Infantilismo }\end{array}$ & $\begin{array}{ll}\text { - } & \text { Paz } \\
\text { - } & \text { Reflexión }\end{array}$ \\
\hline Cuerpo humano & $\begin{array}{ll}\text { - } & \text { Integralidad } \\
\text { - } & \text { Crudeza }\end{array}$ & $\begin{array}{ll}\text { - } & \text { Igualdad } \\
\text { - } & \text { Reivindicación de lo femenino } \\
\text { - } & \text { Realidad } \\
\text { Humanismo }\end{array}$ \\
\hline Urbanismo & $\begin{array}{ll}\text { - } & \text { Orden } \\
\text { - } & \text { Desorden } \\
\text { - } & \text { Caos } \\
\text { - } & \text { Ruptura }\end{array}$ & $\begin{array}{ll}\text { - } & \text { Industrialización } \\
\text { - } & \text { Globalización } \\
\text { Modernidad }\end{array}$ \\
\hline
\end{tabular}

Tabla 7. Elaborado por: Pérez,C \& Rizzo, M. uente: Encuestas realizadas a población asistente a exposiciones, muestras permanentes, seminarios en la ciudad de Guayaquil Ecuador.

Este último grupo temático podría servirnos como puente para entender en qué ha desembocado la búsqueda de los dos grupos anteriores. No podemos afirmar que una tendencia evoluciona en otra, pero sí podemos descubrir que los lenguajes tienden a reubicarse y a conformarse de maneras diferentes en las tendencias que se suceden. Así, la figura del indígena se vuelve más global con la llegada del Conceptualismo, y no se aborda más al indígena en sí mismo, sino al ser humano en toda su amplitud.

Otro síntoma corresponde a la suplantación de la figuración explícita del expresionismo por tendencias mucho más elaboradas en el Arte Contemporáneo, que es capaz de releer y reutilizar lenguajes para generar procesos nuevos en sociedades complejas.

\section{Conclusiones}

La población manifiesta preferencias por artistas y tendencias correspondientes a las décadas del 50 y 60 del Siglo XX. Las tendencias y autores actuales poseen una importancia menor o nula para la población consultada, resultando prácticamente desconocidos. Las temáticas preferentes de la población consultada corresponden a motivos ornamentales que muchas veces son motivo de plagio o trato artesanal dentro del mercado artístico. La población reconoce la importancia del Arte Contemporáneo, aunque desconoce sus manifestaciones. Las propuestas artísticas serias, pensadas desde la intelectualidad, la academia o la praxis artística que se mueve en esferas más allá de lo comercial no adolece de estancamientos, ya que las 
búsquedas contemporáneas corresponden a situaciones muy diversas.

El Arte Contemporáneo muchas veces utiliza el recurso de la interpretación histórica o la relectura de lenguajes artísticos explorados con anterioridad, pero lo hace de una manera crítica.

Aunque existen elementos que podrían parecer repetitivos entre una y otra época, los símbolos finales varían en cuanto a su contenido y forma, evidenciando un proceso de evolución que se hace patente en la mentalidad de los artistas que los generan. Esto es muestra clara de que no existe un estancamiento en la producción artística. Por lo contrario falta aún por crear y plasmar nuevas propuestas artísticas visuales.

En la que los intereses sociales se ven determinados por las prácticas culturales actuales. Sociedad compleja en la que prevalece el consumo, la libertad individual, la cantidad de información, la búsqueda por el placer, el cultivo del cuerpo, la conectividad, la incertidumbre, la movilidad internacional entre otros aspectos.

\section{Referencias}

Andrade, X. (2011). Contra el Efecto Guayasamín. Revista Arcadia. Quito, no .67,p 32-33.

Azuar, R. (2008). Museos del Público al Ciudadano. España: Argitalpen.

Bugler, C. (2010). Arte La guía visual definitiva. Singapur: Editorial DK.

Brunner, J (2003). América Latina: cultura y modernidad. Consejo Nacional para la Cultura y las Artes. México: Editorial Grijalbo S.A.

Chilvers, I. (2010). Arte siglo XX-Actualidad. Singapur: Editorial DK.

Corbetta P, (2003). Metodología y Técnicas de Investigación Social. España: Universidad de Bolonia

Dorling K. (2010). Arte: la guía visual definitiva - actualidad. Londres: Editorial DK.

Eco, U. (2000). Tratado de Semiótica General. Barcelona: Editorial Lumen.

Eco, U. (2007). Perspectivas de una semiótica de las artes visuales. Criterios. La Habana, $n^{\circ} 25-28$, pp. 221-233

Guasch, A. M. (2011). El Arte ultimo del siglo XX, Del posminimalismo a lo multicultural. Madrid: Editorial Alianza Forma.

Kronfle, R. (2009). Historia(s) en el arte contemporáneo del Ecuador. Guayaquil: Río Revuelto Ediciones.

Kronfle, R. (2012). Arte Contemporáneo, en: Río Revuelto. Recuperado el 11 de junio de 2013, de http://www.riorevuelto.net.

Lalama, R. (2011). Ancestros e Identidad. Duran: Editorial Poligráfica.

Maceira, O. (2008). Los públicos y lo público. De mutismos, sorderas y de diálogos sociales en muesos y espacios patrimoniales. España: Editorial Argitalpen.

Magritte, R. (1929) La traición de las Imágenes. Museo de Arte del Condado de Los Ángeles. Los Ángeles: LACMA.

Oliveras, E. (2004). Estética, La cuestión del arte. Argentina: Editorial Ariel Filosofía. Red Nacional de Museos. (2012). Red Nacional de Museos. Recuperado el 21 de Agosto de 2014, de https://dl.dropboxusercontent.com/u4356705/folleto\%20Red. pdf 
Ramos, M. A. (2006). Tratado de pintura de Leonardo Da Vinci. Madrid: Filosofía alianza.

Rodríguez Castello, H. (1988). El siglo XX de las artes visuales en el Ecuador. Guayaquil: Cromos S.A.

Ruhrberg, K. (2003). Arte del siglo XX. España: Océano.

Sistema Ecuatoriano y política Nacional de Museos. (2012). Ministerio de Cultura y patrimonio. Recuperado el 23 de Agosto de 2014, de https:// docs.google.com/file/d/1Lc723KQzylFFjL8vfQeeHDLkptRcegMdMQW_ KFnss7wpSrfQVPY1y3aBdCHD/edit?pli=1.

Vergara, R. (2009). Centros Históricos: El patrimonio como herramienta del Desarrollo Social. Memorias. Colombia, $\mathrm{n}^{\mathrm{o}} .11, \mathrm{p}$ 1-14.

Von der Walde Moheno, L. (1990). Aproximación a la semiótica de Charles S. Peirce. Acciones Textuales . Revista de Teoría y Análisis. México, $n^{o}$. 2, p 90-92.

Walker, J.A. \& Chaplin, J(2002). Una introducción a la cultura visual. Barcelona: Octaedro

Yúdice, G: (2006). El recurso de la cultura. Usos de la cultura en la era global. La Habana: Editorial Ciencias Sociales. 